\title{
Understanding Environmental Policy Preferences: New Evidence from Brazil*
}

\author{
Michaël Aklin ${ }^{\dagger}$ \\ NYU
}

\author{
Patrick Bayer \\ University of Mannheim
}

\author{
S.P. Harish \\ NYU
}

\author{
Johannes Urpelainen \\ Columbia University
}

13 May 2013

\begin{abstract}
We examine the relationship between socio-economic factors and public opinion on environmental policies in Brazil, drawing on a survey conducted in June 2012. There are few systematic studies of the determinants of environmental preferences in emerging economies, and Brazil is a particularly interesting case because of its democratic political system, rapid economic growth, and importance for the global environment. In general, we find that the Brazilian public is highly supportive of environmental protection. To explain variation in environmental preferences, we focus on the effects of income and education. Many previous studies suggest that both should have positive effects, but the empirical evidence is mixed. Indeed, we find that income has no effect on environmental preferences. However, education is a strong predictor of environmental preferences. While college education is not necessary for environmental awareness, there is a large difference between Brazilians with primary and secondary education. For policy, the findings imply that investment in secondary education can raise environmental awareness, regardless of income levels.
\end{abstract}

${ }^{*}$ We thank Leany Lemos for providing us with the survey data. We are thankful to Vivian Coyne, Lisandra Flach, Pedro Silva, Bettina Trueb, and three anonymous reviewers for their helpful comments. All errors remain ours.

${ }^{\dagger}$ Corresponding Author. Department of Politics, New York University. 19 West 4th Street, New York, NY 10012. Email: michael.aklin@nyu.edu. 


\section{Introduction}

This paper analyzes survey data to investigate the relationship between income, education, and peoples' environmental preferences in Brazil. ${ }^{1}$ While there is a voluminous literature on the determinants of environmental preferences in industrialized countries (Stern, Dietz, and Kalof, 1993; Tranter, 1997; Rabe and Borick, 2009; Aldy, Kotchen, and Leiserowitz, 2012), much less is known about this issue in emerging economies. Even though several surveys - for instance, the World Value Survey ${ }^{2}$, the Pew Research Center's Global Attitudes Project ${ }^{3}$, and the Instituto de Estudos da Religião opinion polls ${ }^{4}$, conducted on behalf of the Brazilian Environment Ministry (Ministério do Meio Ambiente) - regularly collect data on environmental preferences in Brazil, the determinants of these preferences remain underexplored. Therefore, we not only provide descriptive statistics on environmental preferences, but emphasize income and education as explanatory variables to examine variation across Brazilians' environmental preferences.

Analyzing income and education as determinants of environmental preferences in a quickly industrializing country like Brazil is important as environmental preferences may systematically differ between developing and developed countries. Tastes may be different; a large body of economic literature suggests that poorer countries place a lower premium on a clean environment (Grossman and Krueger, 1995; Rothman, 1998). Alternatively, people may experience various local environmental problems that are not relevant in industrialized countries.

Brazil is an interesting case for several reasons. First, the importance of emerging powers for global environmental governance is increasingly acknowledged (Aldy and Stavins, 2007; Roberts

\footnotetext{
${ }^{1}$ A supplementary appendix and a replication package will be made available online upon publication.

${ }^{2}$ The most recent 2010-2012 wave of the World Value Survey contains questions on the economy-environment tradeoff, whether money was given to environmental organizations, and whether the respondent participated in a demonstration for some environmental cause. For further details and the data, see http://www.worldvaluessurvey.org/ wvs/articles/folder_published/article_base_116. Accessed on February 23, 2013.

${ }^{3}$ For instance, the "Most Muslim Publics Not So Easily Moved" survey from July 23, 2009, contains questions on whether global warming is considered a very serious problem, whether the environment should be protected even if this costs jobs, whether people would be willing to pay higher prices to address climate change, and which country is trusted the most in international climate policy. See http://www.pewglobal.org/files/pdf/264.pdf. Accessed on February 23, 2013.

${ }^{4}$ The "O Que o Brasiliero Pensa do Meio Ambiente e do Consumo Sustentável" survey, published in October 2001, presents detailed survey results on the economy-environment tradeoff and sustainable development, Brazilians' information levels about environmental issues, and what Brazilians consider as their country's most distinctive environmental asset and as the most pressing environmental problems. For additional details, see www.brazilink.org/tiki-download_file.php?fileId=199. Accessed on February 23, 2013.
} 
and Parks, 2007). From China to India and Brazil, rapid economic growth is increasing resource consumption, waste, and pollution. Second, there is evidence that public opinion is a major determinant of policies in democratic countries (Erikson, Wright, and McIver, 1994; Page and Shapiro, 1983). Since elected officials are more constrained by the preferences of their citizens than non-elected officials, public opinion is a potentially powerful determinant of environmental policy in a democratic country like Brazil (Bernauer and Koubi, 2009). Finally, understanding what shapes the preferences of Brazilians is particularly important. Brazil is one of the ten largest economies worldwide, and second only to China among emerging countries. ${ }^{5}$ The deforestation of the Amazon rainforest is a major source of climate change (Shukla, Nobre, and Sellers, 1990; Araujo et al., 2009). In sum, Brazil is a major economic and environmental player. The emergence of politicians such as the Partido Verde's Marina Silva (Green Party), who gathered almost 20\% of the popular vote to the 2010 presidential elections, underscores the emergence of environmental concerns in Brazil. ${ }^{6}$ Yet, little is known about the Brazilian people's environmental preferences.

To analyze Brazilian public opinion on environmental policy, we draw on a survey conducted by the Brazilian Senate's own survey organization, DataSenado. ${ }^{7}$ The survey is based on a telephone poll of 1,226 Brazilians in 119 municipalities during the period June 1-14, 2012, immediately before the Rio+20 United Nations Conference on Sustainable Development. ${ }^{8}$ We analyze responses to four important questions about environmental policy. Respondents were asked to indicate their level of support for the environmental policies of candidates to public jobs (Question 1), their views about existing environmental regulation (Question 2), their opinion about the trade-offs between economic development and pollution (Question 3), and Brazil's consideration of environmental problems when dealing with other countries (Question 4).

In general, we find the Brazilian people to be highly supportive of the environment. We also find that education has a positive effect on pro-environmental views. The effect is significant for a

\footnotetext{
${ }^{5}$ Data from the IMF's World Economic Outlook Database, accessed on October 20, 2012.

"Brazil election sees breakthrough for Greens and environmental agenda" The Guardian, http://www.guardian . co.uk/world/2010/oct/04/brazil-election-breakthrough-greens.

${ }^{7}$ See http://www. senado.gov.br/noticias/datasenado. Accessed October 8, 2012.

${ }^{8}$ Undoubtedly, the timing increased the population's awareness of environmental issues. However, we are mainly interested in the population's relative preferences, not in how they compare with other countries' populations. Therefore, our main results remain valid as long as the effect of Rio+20 was roughly even across the population. See below for a discussion on the upwards bias that exists in environmental surveys.
} 
range of different preferences over various facets of environmental policy. The results are robust to the inclusion of state fixed effects and several relevant control variables. Given that education is associated with increased awareness about environmental deterioration in the Brazilian context, these results suggest that informational factors play an important role in shaping environmental preferences.

Income, however, does not appear to predict variation in environmental preferences. One reason may be that environmental quality is similarly valued across different segments of the population, from the poorest to the wealthiest. This may result from the fact that many Brazilians are exposed to local environmental degradation, such as land degradation and poor water quality. ${ }^{9}$ In such circumstances, solving environmental issues is perhaps not particularly more valued by the richest. While our survey excludes Brazilians who have no telephone, the sample does contain people who have no formal income.

We examined the data further to understand when education matters. We find that the key educational threshold is at the secondary level. People who completed secondary schooling are significantly more likely to support environmental views than people who only have primary education. However, a college degree does not make people more supportive of the environment than those who completed a secondary education. We also note that education and income are not strongly correlated $(r=0.31)$, thereby suggesting that the negligible income effect is not caused by conflating it with education.

Regarding income, we find evidence suggesting that the middle class is generally more proenvironmental than the poor, while the wealthiest are often less environmentally friendly than the poorest respondents. However, since the effects for income are often not statistically significant, the estimations cannot confirm the presence of such non-linear relationships.

Our study offers new insight into the determinants of environmental preferences among the citizens of a rapidly growing country. We extend existing scholarship on environmental policy, which has largely focused on wealthy countries. Given that emerging powers are now key players in global environmental politics, it is important to understand how their citizens perceive

\footnotetext{
${ }^{9}$ For the relationship between the local environment and happiness, see Brereton, Clinch, and Ferreira (2008).
} 
environmental issues and how these views might evolve. An increasingly educated workforce in Brazil may contribute to the country's adoption of increasingly green positions in multilateral negotiations, especially given Brazil's democratic political institutions.

\section{Environmental Policy Preferences: Income and Education}

The rise of environmental issues has produced a large body of literature studying individual attitudes toward the environment (Franzen, 2003). Specifically, scholars have attempted to identify the main determinants that predict a person's awareness of environmental issues and her willingness to solve these issues. Simplifying this broad scholarship, we focus on two sets of important characteristics: income and education. The rationale for limiting our scope is that environmental issues have complex origins and consequences (Brown, Harris, and Russell, 2010) and solving them is generally costly.

\subsection{Income and Education}

Although economic growth is often associated with pollution (Meadows, Randers, and Meadows, 2004), various academic disciplines have long suspected that income favors pro-environmental views. The environmental Kuznets curve hypothesis posits that environmental degradation follows an inverted-U shaped trajectory as a country's income grows (Grossman and Krueger, 1995; Galeotti, Lanza, and Pauli, 2006). Income changes people's preferences and strengthens the government's incentive to reduce negative environmental externalities, including pollution and waste (Dasgupta et al., 2002).

The link between income, values, and environmental preferences has also been recognized by scholars studying public opinion. Early findings seemed to suggest a negative relationship between income and environmental concern. Dunlap and Mertig (1995) aggregate responses from the Health of the Planet survey at the national level and find a negative bivariate correlation between income per capita and environmental concern. These findings were soon subsumed by numerous studies that showed, however, a robust positive relationship between individual welfare and environmental preferences. Proponents of the 'affluence hypothesis' present evidence that wealthier individuals are more willing to forgo some of their income for a cleaner 
environment. Diekmann and Franzen (1999) analyze data from the 1993 International Social Survey Programme (ISSP) and find a positive bivariate correlation between income per capita and environmental preferences. Franzen (2003) draws on a 2000 ISSP survey and finds that environmental concern at the national level increases with wealth, but not in a linear way; recent growth in the 1990s did not lead to additional reported concern about the environment. Other scholars have examined within-country variation of environmental views. Kemmelmeier, Król, and Kim (2002) study the 1993 ISSP data on a country-by-country basis and find that wealthier individuals are more willing to invest in a cleaner environment, but they argue that income mainly has an indirect effect by changing values and not only by making environmental concern more affordable. They also find that education has a positive effect on environmental preferences in most countries in the sample.

This argument is related to post-materialism (Inglehart, 1995, 1997), which contends that individuals' values shift with their affluence. Wealthier people are more likely to value a clean environment and be able to afford it, since it often comes at some economic cost. Inglehart (1995) examines data from the World Value Survey and obtains ambiguous findings. While citizens from wealthier countries are more likely to have taken concrete actions to protect the environment, the level of concern is also high in poor countries. Inglehart suggests that environmental concern can come both from a change in values through increased income and from being at risk of environmental degradation due to a low income. Using country-level data, Knight and Messer (2012) provide support for the idea that vulnerability to environmental issues is an indicator for a country's average willingness to pay for a cleaner environment.

Empirically, Franzen and Meyer (2010) provide evidence that corroborates both the affluence and the post-materialistic argument. Using a multilevel approach and drawing on ISSP data from 2000, they find that the wealthiest segment of each country tends to be more concerned about the environment. The effect of education is generally also positive, though the results fluctuate more and are not always statistically significant. They find that countries that are richer tend to exhibit higher degrees of pro-environmental preferences. Further, they also provide evidence suggesting that changing values may play a role in environmental attitudes. Overall, this reflects both the 
notion that income has a direct effect, in terms of the ability to pay for a cleaner environment, and an indirect effect, by increasing the relative importance of non-materialistic preferences.

Finally, an additional strand of literature examines the opposite causal story. Using survey data from Switzerland, Bechtel, Bernauer, and Meyer (2011) ask whether individuals that are more concerned about the environment are more likely to be willing to engage in restrictive economic policies, such as trade restrictions. They find this to be the case, though the effect is only significant for people self-identifying as having leftist preferences.

Since environmental issues are complex problems that have mainly attracted the scientific community's attention, it seems intuitively plausible that knowledge and education may also be an important predictors of pro-environmental attitudes. Liere and Dunlap (1980) offer an early review of the evidence on education and environmental preferences. The literature that they consult on education suggests a positive correlation between the level of education and a range of variables capturing environmental concern, although they provide no information about the statistical significance of these findings.

Franzen and Meyer (2010) perform a cross-national survey analysis of environmental attitudes in a dataset of emerging and industrialized countries. Using a multilevel regression analysis, they find that education is generally positively related to environmental concern. However, they find that the relation may not necessarily be linear; rather, it is exponential in some models, while it follows a U-shaped path in some specifications.

These cross-national studies have been augmented by analysis at national and subnational levels. Using representative survey data from Australia, Tranter (1997) finds that tertiary education is positively associated with environmental activism. Based on a survey in Kentucky, Arcury (1990) finds that more educated respondents know more about environmental issues and are more willing to engage in pro-environmental reforms. Liu, Ouyang, and Miao (2010) provide evidence that education matters in emerging countries, too. Examining the case of the Protected Area of Junyun Mountain in China, they find that education levels significantly predict pro-environmental attitudes.

The consensus on education is not perfect, however. Cotgrove and Duff (1981) offer a more 
nuanced perspective, suggesting that 'industrialist' individuals who derive their livelihood from possibly polluting activities tend to be highly educated, too. Indeed, considering the case of

climate change, Kahan et al. (2012) provide survey evidence from the U.S. that more knowledge does not translate into higher support for scientific work. Rather, the effect is contingent on political preferences.

\subsection{Income, Education, and Environmental Concern in Emerging Countries}

Overall, little is known about whether the findings from industrialized countries are externally valid for emerging countries as well. The data analyzed so far generally stem from a fairly small set of countries that are fairly homogeneous. We do not know whether these results would hold in a different setting. There are a few noteworthy exceptions. Bloom (1995) uses Gallup data from 1992 and the "Public and Leadership Attitudes to the Environment in Four Continents" survey from 1988-1989. He finds that respondents from developing countries are more likely to worry about local pollution, and about equally likely to consider global environmental problems as being important. Dunlap and Mertig's (1995) study contained six low income and seven middle income countries. However, their study aggregates responses at the national level and does not explain individual support for the environment. More recently, Ignatow (2005) examines support for environmental protection in Turkey. He finds little evidence that individual wealth shapes environmental preferences.

Differences may emerge for many reasons. First, tastes may differ. The public's preferences for public goods, in particular environmental goods, may be very different in non-Western countries. Second, the literature cited above suggests that the degree of economic development affects preferences. Yet, these findings concentrate on a fairly small number of highly developed countries. But, how can we explain these within-country differences in emerging countries? The environmental scholarship offers little guidance here.

We explore these questions drawing on survey data from Brazil. In light of the reviewed literature, we offer two hypotheses concerning the relationship between Brazilians' attitudes toward the environment and their (i) income and (ii) education. First, based on the vast literature on the effects of income on environmental preferences, we examine the effect that peoples' income 
has on their responses. A clean environment has a high positive income elasticity according to the post-materialistic scholarship and the affluence hypothesis (Diekmann and Franzen, 1999; Inglehart, 1995).

This ought to be even clearer among a population that is poorer than those analyzed in the extant literature. Higher degrees of income increase the share of income that can be spent on non-essential goods, such as environmental (public) goods. We expect environmental goods to exhibit high income elasticity, at least for the poorest segments of the population. Since poorer individuals have little disposable income, their willingness to spend on environmental goods is limited. Their primary concerns pertain to basic needs, such as shelter and food. While environmental issues often have an effect to poor people due to higher vulnerability, we expect concerns about environmental risk to be channeled through concerns about basic needs. Wealthier people, instead, can due to their affluence afford to worry about environmental issues for their own sake. For these reasons, we expect income to have a positive effect on attitudes toward environmental issues.

Hypothesis 1 (Income and environmental preferences). Environmental concern increases with income.

We acknowledge two main counterarguments against this idea. First, wealthy individuals may be able to invest in private mitigation, such as relocating to areas with little pollution, instead of paying for regulations that protect the national environment. In this case, the effect of income on environmental policy preferences may be suppressed. Although wealthy individuals prefer a clean environment, they may want it for themselves, with less concern for the environment in which the poor live. Second, Brazil's high levels of income inequality and economic structure based on natural resources (Hochstetler and Keck, 2007) may lead wealthy individuals to conclude that they would have to pay a heavy price for environmental regulation (Hotte and Winer, 2012). In this case, they may oppose environmental policy despite an intrinsic preference for a clean environment. If they would have to significantly change their behavior, the cost could be too high, especially in conjunction with the possibility of private mitigation discussed above.

Additionally, we suggest that education helps people recognize and identify environmental 
issues. In a world where individuals operate under cognitive limitations, additional information in the form of formal education ought to increase people's awareness of environmental problems.

The rationale of this argument can be expanded as follows. Individuals operate under incomplete and imperfect information. Acquiring information is costly, making partial ignorance rational (Downs, 1957; Simon, 1997). Public education is one way to provide useful information at a low cost. Schooling teaches individuals about environmental degradation, which is particularly important since many environmental issues are hidden: they may be very localized, their causal relation to human activity may be unclear, or their occurrence may be delayed in time. Since individuals cannot directly experience environmental harm for these types of environmental problems, information and awareness are necessary for environmental concern. For example, Brazilians who do not live in the Amazon do not directly experience deforestation. If they have high levels of education, however, they can connect land use change, deforestation, and various local and global environmental problems.

A second reason that could explain the effect of schooling is higher education's effect on people's values. For instance, a good education may lead individuals to build a set of ethical principles that might be more environmentally conscious. If the curriculum discusses natural resource management and pollution from an ethical perspective, individuals can more readily internalize the complex arguments that underpin intergenerational equity and sustainability.

Finally, schooling may increase people's trust in science and make them more responsive to the worries regularly put forward by the scientific community. People with higher levels of education are more familiar with the scientific method, and therefore they are more receptive to warnings by scientists about the lack of environmental sustainability in contemporary Brazil.

Hypothesis 2 (Education and environmental preferences). Environmental concern increases with education.

Education could have an effect on environmental policy preferences at different levels. First, college education could be critical because it focuses on higher learning. College students can enroll in classes that deal with environmental science or complex ethical issues related to the environment. In this telling, the highest levels of education are particularly conducive to envi- 
ronmental awareness. On the other hand, it could be that secondary education - high school or vocational - could be enough. Already at this level, students can learn about the basic functioning of natural systems and their relevance for human wellbeing. According to this view, basic awareness suffices to shape environmental policy preferences, and higher learning is not necessary for the effect to materialize.

\section{Research Design}

Brazil is one of the most influential emerging countries. A democracy since 1985, the country's population of roughly 200 million has grown by 32\%, and its economy has expanded by $62 \%$ since $1990 .{ }^{10}$ This has led commentators to suggest that Brazil is now one of the most influential emerging democracies at the regional and international level. ${ }^{11}$

Brazil's growth, although generally lower than that of other emerging countries, also transformed it into one of the world's premier polluters. Its carbon dioxide emissions, while only representing $1 \%$ of the world's total emissions, places the country among the 20 largest emitters. ${ }^{12}$ Further, its influence as a greenhouse gas emitter is likely to increase as both its population and its income rises. Importantly, Brazil's greenhouse gases stem in a relative large proportion from changes in land use, not from energy consumption (Johnson, 2001). Indeed, Brazil relies heavily on biofuels and hydroelectric power. The deforestation of the Amazon both immediately releases carbon in the atmosphere and reduces the planet's capacity to provide carbon sinks (Johnson, 2001: 86). Besides global climate change, Brazil also suffers from local environmental issues. The country suffers from problems that are typical of rapidly growing countries, such as air pollution (Anderson, 2009) and water pollution (Martinelli and Filoso, 2008).

The literature on public opinion teaches us that democratic political institutions tend to induce officials to reflect the views of their citizens (Erikson, Wright, and McIver, 1994; Page and Shapiro, 1983). If they want to be reelected, officials must listen to their population's demands.

\footnotetext{
${ }^{10}$ Data from the Penn World Tables 7. Accessed on October 25, 2012.

${ }^{11}$ For instance, Brazil has sought more influence in the management of international institutions such as the IMF. “Brazil Seeks More IMF Influence After Loan Promise: Week Ahead" Bloomberg, April 19, $2009 . \quad$ See http://www. bloomberg.com/apps/news?pid=newsarchive\&sid=aApYqdODdNfY\&refer=news. Accessed on November 1, 2012. Alternatively, "BRIC has growing world influence" China Daily, April 16, 2010. See http://www. chinadaily. com.cn/china/2010-04/16/content_9737299.htm. Accessed on November 1, 2012.

${ }^{12}$ Data from the World Resource Institute's CAIT 8 dataset. Accessed on October 12, 2012.
} 
Elections offer a cheap way for citizens to replace officials who do not further policies that are agreeable to them. Though not conclusive, evidence suggests that democracies are responsive to the demands of voters (e.g., Lax and Phillips, 2009).

Since public policy is conditioned by voter preferences in democracies and little is known about what determines Brazilians' environmental preferences, understanding the preferences of the country's citizens with respect to the environment offers a potentially large payoff. This paper analyzes data from a survey that was conducted in Portuguese between June 1-14, 2012 by DataSenado for the United Nations Conference on Sustainable Development held in Rio de Janeiro on June 20-22, 2012. Since the conference was widely announced, undoubtedly some respondents were aware of the upcoming event and possibly also more aware of environmental issues.

A total of 1,226 respondents were surveyed by telephone on their environmental policy preferences. All respondents were residents of Brazil, at least 16 years old, and had access to a landline telephone. The sampling strategy involved two stages. The first stage uses probabilistic sampling, where state capitals were chosen with probability one and Brazilian municipalities were selected with a probability equal to their population. This resulted in a total of 119 municipalities, including 26 state capitals and the Federal districts. The second stage of the sampling process drew landline telephone numbers using quota sampling since there does not exist a master list with all landline numbers. The margin of error for the survey is $3 \%$, and trained professionals checked $20 \%$ of the interviews as quality audit. Missing data forces us to drop between 11 and 60 observations depending on econometric model specifications, which is, however, a benign number by the standards of survey analysis.

While the survey methodology used by DataSenado for gathering survey information on environmental preferences across Brazil ensures geographical stratification, our sample overrepresents the rich and better educated compared to Brazilian census data. Since income and education are our key explanatory variables, the non-representativeness of the sample may bias our results. We account for this problem econometrically by re-estimating all our models with 
sampling weights, which we constructed to reflect the Brazilian 2010 census data. ${ }^{13}$ In the supplementary appendix, to which we relegate a detailed description of how sampling weights are constructed, we show that our results hold by and large. Since the increase in standard errors is an immediate consequence of the weighting up of rare combinations of income and education, the robustness of our findings confirms that the results are not driven by biased sample selection.

\subsection{Dependent Variable}

In choosing our dependent variables, we rely on two approaches. On the one hand, we report results on substantively central outcome questions from the survey. The strength of this approach is that we scrutinize the robustness of our findings across a wide range of measures that should produce similar results. On the other hand, we also follow Dunlap et al. (2000) in building an index of environmental concern. This approach allows us to aggregate results from various questions, which is particularly important in case the findings for different questions conflict with each other. With a total of five different dependent variables, we are able to deal with imperfections in measurement. For example, the question on considering environmental issues in voting could, at least in principle, lead some anti-environmental respondents to answer in the positive.

Table 1 summarizes the questions that we examine. It also contains our coding scheme. For all dependent variables, higher values indicate a more pro-environmental stance by the respondent. For the analysis, we selected four questions from the survey. They pertain to the recipient's opinion on (1) the importance of a candidate's environmental policy proposals before voting, (2) environmental legislation in Brazil, (3) the economy-environment trade-off, and (4) the importance of the environment during international negotiations.

\section{[Table 1 about here.]}

Table 2 provides summary statistics for the different dependent variables along with the explanatory and control variables used in this study. In the appendix, we present the correlation matrix for all these variables. Notice that while the dependent variables describe various facets of

\footnotetext{
${ }^{13}$ See ftp://ftp.ibge.gov.br/Censos/Censo_Demografico_2010/Educacao_e_Deslocamento/pdf/tab_ educacao.pdf, Tabela 1.1.15 for the relevant information. Accessed on February 28, 2013.
} 
the respondents' environmental preferences, their actual correlation coefficients are fairly low, albeit positive and statistically significant. This means that each question contains an independent signal that can be used to test our two hypotheses.

[Table 2 about here.]

Notice that since each question was presented without reference to any negative countermessage, such as one about the cost of environmental regulation (Aklin and Urpelainen, 2013), and since environmental issues suffer from social desirability bias (Himmelfarb and Lickteig, 1982), it is not surprising that the answers are on average more pro- than anti-environment. In addition, as we indicated above, the survey was conducted shortly before the Rio Conference, which might have increased the salience of environmental issues among the Brazilian population. However, given our interest in the variation of preferences in a single country, this should not threaten the reliability of our results as long as the effects operate in a similar manner across the Brazilian population.

Finally, we performed a factor analysis using the responses to the four questions to derive a single index of pro-environmental views for each respondent. The correlation coefficient between the factor score and each of the four other dependent variables ranges between $r=0.44$ and $r=0.67$. The factor score ranges from -3.3 to 0.42 , with a mean of almost zero. Higher values denote a more pro-environmental position. The first dimension of the factor is then used as a dependent variable.

\subsection{Explanatory Variables}

There are two key explanatory variables in this study, education and income. The data do not provide exact figures for either variables. For instance, we do not know how many years of formal education each respondent got. However, the survey provides ordinal measures.

The first main variable is income. It is coded on an ordinal scale in 5 categories. The lowest category, which receives the value 1 , denotes individuals who do not receive any income. The next category indicates that the respondent receives up to twice the federal minimum wage. The 
minimum wage in 2012 was set at roughly 622 Reais, or US\$306 per month. ${ }^{14}$ The third category receives between two and five times the minimum wage; the fourth receives between five and ten times the minimum wage; and the final category receives more than ten times this amount. The mean value of 2.42 suggests that the respondents on average received between one and five times the minimum wage. In line with the affluence hypothesis, we expect income to have a positive effect on environmental preferences.

Since the ordinal category is somewhat crude, especially at the highest levels, we also replicated the analysis while excluding the lowest or highest values. This is important because if income had nonlinear effects, it would be important to have an accurate measure of respondents' wealth levels. The results reported in the appendix suggest, however, that the finding is not driven by any particular wealth level, be it high or low.

Education of the respondent is recorded in three categories, ranging from primary and secondary education to college degree, coded again on an ordinal scale. The value 1 is used for respondents up to completed primary education, 2 for those who finished their secondary education, and 3 for respondents who went to college. The sample's average value is 1.9, suggesting that a fair amount of respondents did not get a formal education beyond primary school.

For this variable, the main measurement concern is that it does not distinguish between people who had some college education and those that finished a degree. Therefore, we also replicated the analysis while excluding this category altogether. We found that there is a significant difference across lower levels of education, suggesting that the imprecise measurement of tertiary education is not a major problem.

As we show in the appendix, the correlation between education and income is positive and significant. This is not surprising, since education allows people access to better paying jobs. Importantly, this could lead to multicollinearity. While multicollinearity would not bias our estimates, it would increase their standard errors. Fortunately, post-estimation diagnostic tests show that multicollinearity is not a problem in our estimation. The Variance Inflation Factor (VIF) score, a measure of multicollinearity, never goes above 3 for our two variables in any of our

\footnotetext{
${ }^{14}$ Exchange rate on October 20, 2012. See "Brazil May Increase Minimum Wage to 622.73 Reais in 2012", Bloomberg News, November 22, 2011. Accessed on October 11, 2012.
} 
specifications. Furthermore, we re-estimate all models removing either income or education; we find that our results still obtain. A complete cross-tabulation for income and education is also provided in the supplementary appendix.

\subsection{Control Variables}

We include other possible variables, such as age, gender, and the location of the respondent as control variables to our models. All variables were collected as part of the survey itself.

Many environmental problems are long-term issues. Intuitively, it would seem reasonable that a respondent's age, and thus potential exposure to future environmental degradation, may affect environmental preferences. For example, Franzen and Meyer (2010) find that age has a detrimental effect on environmental preferences. While the exact age of the respondents in our survey was not recorded, we know to which cohort they belong. Cohorts are defined by decades. Respondents under 20 are given a value of 1, those in their twenties are coded as 2, and so forth. The last category, 6, includes all respondents older than 60 years. The main results assume that the effect of age cohort is linear; robustness checks show that our results hold even if we use one dummy variable for each cohort. The average age is 3.57 on our ordinal scale, meaning that the average respondent was in her thirties. In the appendix, we replicate our results for respondents who are above 20 years old, the rationale being that younger respondents may not have had the opportunity to complete their education yet. Our results remain unaffected by this.

Gender has been shown to be correlated with numerous political and social preferences (Stern, Dietz, and Kalof, 1993; Zelezny, Chua, and Aldrich, 2000). In our analysis, gender is a simple dummy variable. We define 1 to be a female respondent. The sample contains slightly more women $(53 \%)$ than men.

Finally, there might be some unobserved effects correlated with geographical location. For instance, some regions might be more vulnerable to environmental problems. We account for geographical factors in two ways. First, we include two categorical dummy variables that indicate if the respondents were living in a state capital or a state municipality. The omitted category contains people living in rural areas. It seems intuitively plausible that individuals living in cities or in the countryside differ in terms of their exposure to and preferences toward environmental 
problems, perhaps because of their occupation. For example, farmers and foresters could be opposed to land use regulations.

Second, we include state fixed effects. The fixed effects account for systematic geographical, economic, and cultural differences across Brazilian states. All our models include these fixed

effects, although we do not report them for lack of space. We also replicated our results using region fixed effects and no fixed effects at all. The results, which are identical in all respects, can again be found in the appendix.

We acknowledge that the survey did not record variables that may have been potential confounders. For instance, we do not know the respondents' professional activity, which may affect their responses. However, state and municipal type fixed effects help by controlling for the nature of the local economy. Another concern pertains to partisan ideology. For example, respondents who affiliate with leftist parties could be more supportive of regulation. This would be an issue if education or income were correlated with partisan affiliation. However, a previous study by Samuels (2006) suggests that this is not the case. His survey analysis from 2002 shows that partisan affiliation in Brazil is less common than in other countries, with only $35 \%$ of the population considering themselves partisan, instead of the $40 \%$ average across the world. Controlling for other factors, income and education also do not explain partisan affiliation. The only exception is that income reduces the likelihood of affiliation with the Brazilian Democratic Movement Party. Since this party does not have a distinct left-wing or right-wing ideology, the association does not suggest an omitted variable bias. Of course, we acknowledge that this association should be systematically tested in future studies of environmental preferences in Brazil.

\subsection{Model}

We estimate a fixed effects model for each of the four survey questions. The models have the following form:

$$
\text { Environmental Concern } i=\alpha+\beta_{1} \text { Income }_{i}+\beta_{2} \text { Education }_{i}+\gamma^{\prime} \mathbf{X}_{i}+\phi \text { State }_{s}+\varepsilon_{i}
$$


where $i$ and $s$ denote the respondent and state, respectively. The vector $\mathbf{X}$ includes the individuallevel control variables listed above, while State $_{s}$ captures state fixed effects. The parameters of interests are $\beta_{1}$ and $\beta_{2}$, both of which are expected to be positive. All models are estimated with least squares (OLS), except our third question, which is estimated with a logistic link function. In the appendix, we use an ordered probit model, with very similar results. Since OLS is easier to interpret, we report these estimates here. Finally, statistical tests have suggested the presence of heteroskedasticity, which is why we report robust standard errors for all our specifications.

\section{Findings}

We first discuss our main findings and then report some additional analyses. Overall, we find little evidence that income shapes environmental preferences of Brazilian respondents. However, their education level is a significant predictor of environmental interest. The more education an individual has, the more pro-environment she is expected to be. A further analysis shows that the education effect materializes when individuals complete their secondary education. Respondents that complete tertiary education are not more pro-environment than individuals who only hold a secondary education degree.

\subsection{Main Results}

The main results are reported in Table 3. The responses to each of the four questions are estimated with and without control variables, while state fixed effects are always included. The first four columns as well as the last four are linear models, and columns 5 and 6 report logistic regression estimates. Recall that we expect both income and education to have a positive effect on environmental preferences.

[Table 3 about here.]

Our results for education are unambiguous. We find that for all dependent variables, education is positively and statistically significantly correlated with environmental concern. This finding is not driven by state-specific effects and is robust to the inclusion of age, gender, and location controls. They are obtained for each questions as well as for our composite index. 
Beginning with our first question, which is measured on a five-point scale, we find that education significantly affects how candidate's environmental policy proposals are valued, whereas income does not. Being more educated, e.g., having a secondary degree instead of only primary schooling, increases the dependent variable by 0.2 units, equivalent to one sixth of this variable's standard deviation. Income has no such effect.

The second question is about environmental regulations in Brazil. It is coded on a three-point scale, where higher values indicate that respondents prefer stronger laws protecting the environment. Again, the results provide clear support for the educational hypothesis, with significantly positive effects being found in all models. A one unit increase in education levels, raises a respondent's desire for stringent environmental regulation by one tenth of a standard deviation. No effect as to the importance of income is detected.

The third question asks whether the respondent agrees or disagrees with the notion that the Brazilian government should allow pollution to increase for the sake of its economic development. The binary response is coded as 1 if the individual disagrees, meaning that she does not think that development should take precedence over environmental concerns. Using logistic regression, we calculate the predicted probability for being pro-environmental. As the substantive effects plot in the appendix shows, increasing education levels from lowest to highest, increases pro-environmental preferences, on average, by about $4 \%$ points. While this effect is non-trivial and statistically significant, income does not predict variation in responses well.

The last question focused on the respondents' preferences with respect to Brazil's conduct during international negotiations. Here, education increases the mean response to Brazil's consideration of the environment in international relations by 0.03 to 0.05 points on a $0-2$ scale. Income, on the other hand, has no observable effect. Moreover, notice that for income the sign of our estimate switches depending on the exact model specification.

Finally, the same results are observed when considering our index derived from a factor analysis. While it is difficult to interpret the index in itself, we find that being more educated increases the value of the index by $1 / 5$ th to $1 / 4$ th of its standard deviation. The effect is significant in all specifications. 
Taken together, our results consistently lend support to Hypothesis (2), but not Hypothesis (1). Education is a positive predictor of pro-environmental attitudes, and the effect is always statistically significant. Since the measurement of our dependent and independent variable differs from other studies, it is difficult to compare the magnitude of the effects. However, we note that we find a monotonic effect of education, unlike Franzen and Meyer (2010) who, in some specifications, find a U-shaped relation between education and environmental concern. In contrast, income does not have any effect on the respondents' views toward the environment. In light of the abundant literature suggesting that income matters for environmental preferences, this non-effect is puzzling at first sight. However, it may capture the inconsistent effects of income. While high income may increase the value of the environment as a good that the poor cannot afford (Franzen and Meyer, 2010; Grossman and Krueger, 1995), the poor may at the same time be more vulnerable to environmental hazards (Dunlap and Mertig, 1995). If these two effects are equally strong in Brazil, the reported non-effect can be rationalized ex post.

\subsection{Further Analyses}

Given these initial findings, we want to better understand which level of education matters the most. Also, we want to carefully examine if the non-finding on income is really due to this variable's inability to predict environmental preferences, or may potentially be due to nonlinearities that our previous model specifications could not adequately capture. If independent variables were to operate in a non-linear fashion, the results from above would be biased. To foreshadow, we find that non-linear model specifications produce results similar to those from linear estimation. Income continues to be insignificant, whereas education has a positive effect on environmental interests; completing secondary education is found to have the strongest effect.

For this analysis, we create dummy variables for each category of our education and income variable. To avoid perfect multicollinearity, we use $k-1$ categories, with the lowest level of educational attainment and the no income group being the baseline categories; all point estimates are thus to be interpreted relative to this omitted baseline. While dropping the linearity assumption makes our models more general, the small number of cases in some categories inflates the size of the estimated confidence intervals. The main results from this analysis are reported in Table 4, 
where the same set of controls and estimation techniques are used as above.

[Table 4 about here.]

For education, we find that the main effect kicks in once secondary education is obtained, while the additional increase in environmental concern from secondary and college education is almost negligible. In a country like Brazil, this makes the middle class the most likely supporters of pro-environmental attitudes.

As for income, we detect some evidence of an inverted-U shaped relationship to environmental concern. Those with income levels between two and five minimum wages, roughly at the mean of the sample, are more pro-environmental than the poorest respondents of the survey. In addition, we find that the wealthiest individuals with salaries of more than ten minimum wages hold less pro-environmental positions than the poorest respondents with no income at all. These estimates are always negative, but mostly statistically insignificant. The lower middle class seems to be the most likely to support environmental views and regulations.

Why might this be the case? Some previous survey studies suggest that wealthier individuals often have negative environmental perceptions (Dunlap and Mertig, 1995), while others find the opposite to be true (Franzen and Meyer, 2010). In the Brazilian context, wealthy individuals, such as large ranchers and industrialists, depend for their livelihoods on activities that cause environmental degradation. This may explain why we find evidence for negative environmental perceptions among the wealthy. As to the poorest, proponents of the environmental Kuznets curve have proposed that at low income levels, individuals have more pressing concerns than the environment (Grossman and Krueger, 1995). Our findings offer slight support for these claims, going against the view that the poor are interested in environmental affairs because they are

vulnerable to environmental risks (Dasgupta et al., 2006) and dependent on natural resources (Cavendish, 2000).

\section{Conclusion}

In this paper, we examined the determinants of public opinion about four important views on environmental policy. We focused on the effects of income and education, since theoretical scholar- 
ship suggests that these are central factors that determine environmental views. We investigated these questions using survey data from Brazil. We find unambiguous support for the hypothesis that education has a beneficial effect on pro-environmental preferences. The effect takes place for individuals who completed secondary education. The added contribution of college education is minimal.

Unlike many studies (Diekmann and Franzen, 1999; Franzen, 2003), we find little support for the idea that income has a linear effect on environmental preferences. The estimated coefficients in our main models are insignificant. In light of previous studies, one plausible explanation for this non-effect is that income both increases people's valuation of the environment as a luxury good and reduces their vulnerability to risks (Dunlap and Mertig, 1995; Grossman and Krueger, 1995; Franzen and Meyer, 2010). Allowing for nonlinear relationships, we find tentative evidence of an inverted-U shaped effect of income, whereby the middle class tends to be more favorable to environmental policies. The wealthiest respondents tended to be the least environmental individuals. While this evidence is not conclusive, further research on nonlinearities appears warranted.

Overall, we make two main contributions. First, we offer new evidence on the socio-economic determinants of environmental preferences. We show that education is a key determinant of public opinion about the environment in Brazil. This augments an increasing literature on the positive effects of education on environmental concern (Franzen and Meyer, 2010). Second, we provide one of the first quantitative survey studies on the views of citizens from an emerging country. Despite growing importance for the future of global environmental regulation, little is known about individuals' preferences from these countries. As Brazil may reasonably be expected to become one of the most important countries for the production of global environmental public goods, understanding what drives their citizens' preferences is key. This is particularly true for democracies in which domestic voters have a non-trivial impact on policymaking.

Two questions arise from there. First, what does our study tell us about environmental preferences in other emerging countries? With the rise of large regional and global powers such as China, India, or Indonesia, the need for a clearer view of environmental preferences in these 
local agents is tremendous. Nonetheless, the Brazilian case may suggest that informational effects dominate over income effects. Therefore, an affordable education system, with as little political interference as possible, is needed for increased environmental awareness. Thus, our findings are likely to exert more leverage in democracies like India than compared to China.

Second, what are the policy implications of our findings? Our results suggest that education is a key driver of pro-environmental views. Governments interested in promoting environmental awareness should invest in public education. Encouragingly, the lack of clear income effects suggests that such investments could also enhance environmental awareness among the poor. Increased wealth seems to be neither necessary nor sufficient for environmental awareness. The nonlinear models also suggest that the move from primary to secondary education suffices to cause an effect. A college education, which remains beyond the reach of large segments of people in developing countries, is not necessary for improved environmental awareness. 


\section{References}

Aklin, Michaël, and Johannes Urpelainen. 2013. “Debating Clean Energy: Frames, Counter Frames, and Audiences." Forthcoming, Global Environmental Change.

Aldy, Joseph E., Matthew J. Kotchen, and Anthony A. Leiserowitz. 2012. "Willingness to Pay and Political Support for a US National Clean Energy Standard." Nature Climate Change 2 (8): 596-599.

Aldy, Joseph E., and Robert N. Stavins, eds. 2007. Architectures for Agreement: Addressing Global Climate Change in the Post-Kyoto World. New York: Cambridge University Press.

Anderson, Larry G. 2009. "Ethanol Fuel Use in Brazil: Air Quality Impacts." Energy E Environmental Science 2: 1015-1037.

Araujo, Claudio, Catherine Araujo Bonjean, Jean-Louis Combes, Pascale Combes Motel, and Eustaquio J. Reis. 2009. "Property Rights and Deforestation in the Brazilian Amazon." Ecological Economics 68 (8-9): 2461-2468.

Arcury, Thomas A. 1990. "Environmental Attitude and Environmental Knowledge." Human Organization 49 (4): 300-304.

Bechtel, Michael M., Thomas Bernauer, and Reto Meyer. 2011. “The Green Side of Protectionism: Environmental Concerns and Three Facets of Trade Policy Preferences." Review of International Political Economy .

Bernauer, Thomas, and Vally Koubi. 2009. "Effects of Political Institutions on Air Quality." Ecological Economics 68 (5): 1355-1365.

Bloom, David E. 1995. "International Public Opinion on the Environment." Science 269 (5222): 354-358.

Brereton, Finbarr, J. Peter Clinch, and Susana Ferreira. 2008. "Happiness, Geography, and the Environment." Ecological Economics 65 (2): 386-396.

Brown, Valerie A., John A. Harris, and Jacqueline Y. Russell. 2010. Tackling Wicked Problems. London: Earthscan.

Cavendish, William. 2000. "Empirical Regularities in the Poverty-Environment Relationship of Rural Households: Evidence from Zimbabwe." World Development 28 (11): 1979-2003.

Cotgrove, Stephen, and Andrew Duff. 1981. "Environmentalism, Values, and Social Change." British Journal of Sociology 32 (1): pp. 92-110.

Dasgupta, S., B. Laplante, H. Wang, and D. Wheeler. 2002. "Confronting the Environmental Kuznets Curve." Journal of Economic Perspectives 16 (1): 147-168.

Dasgupta, Susmita, Kirk Hamilton, Kiran D. Pandey, and David Wheeler. 2006. "Environment During Growth: Accounting for Governance and Vulnerability." World Development 34 (9): 1597-1611. 
Diekmann, Andreas, and Axel Franzen. 1999. "The Wealth of Nations and Environmental Concern." Environment and Behavior 31 (4): 540-549.

Downs, Anthony. 1957. An Economic Theory of Democracy. New York: Harper.

Dunlap, Riley E., and Angela G. Mertig. 1995. “Global Concern for the Environment: Is Affluence a Prerequisite?" Journal of Social Issues 51 (4): 121-137.

Dunlap, Riley E., Kent D. Van Liere, Angela G. Mertig, and Robert Emmet Jones. 2000. “New Trends in Measuring Environmental Attitudes: Measuring Endorsement of the New Ecological Paradigm: A Revised NEP Scale." Journal of Social Issues 56 (3): 425-442.

Erikson, Robert S., Gerald C. Wright, and John P. McIver. 1994. Statehouse Democracy: Public Opinion and Policy in the American States. New York: Cambridge University Press.

Franzen, Axel. 2003. "Environmental Attitudes in International Comparison: An Analysis of the ISSP Surveys 1993 and 2000." Social Science Quarterly 84 (2): 297-308.

Franzen, Axel, and Reto Meyer. 2010. "Environmental Attitudes in Cross-National Perspective: A Multilevel Analysis of the ISSP 1993 and 2000." European Sociological Review 26 (2): 219-234.

Galeotti, Marzio, Alessandro Lanza, and Francesco Pauli. 2006. "Reassessing the Environmental Kuznets Curve for $\mathrm{CO}_{2}$ Emissions: A Robustness Exercise." Ecological Economics 57 (1): 152163.

Grossman, Gene M., and Alan B. Krueger. 1995. "Economic Growth and the Environment." Quarterly Journal of Economics 110 (2): 353-377.

Himmelfarb, Samuel, and Carl Lickteig. 1982. "Social Desirability and the Randomized Response Technique." Journal of Personality and Social Psychology 43 (4): 710-717.

Hochstetler, Kathryn, and Margaret E. Keck. 2007. Greening Brazil: Environmentalism in State and Society. Durham: Duke University Press.

Hotte, Louis, and Stanley L. Winer. 2012. "Environmental Regulation and Trade Openness in the Presence of Private Mitigation." Journal of Development Economics 97 (1): 46-57.

Ignatow, Gabriel. 2005. "Economic dependency and environmental attitudes in Turkey." Environmental Politics 14 (5): 648-666.

Inglehart, Ronald. 1995. "Public Support for Environmental Protection: Objective Problems and Subjective Values in 43 Societies." PS: Political Science and Politics 28 (1): 57-72.

Inglehart, Ronald. 1997. Modernization and Postmoderinzation: Cultural, Economic, and Political Change in 43 Societies. Princeton, NJ: Princeton University Press.

Johnson, Ken. 2001. "Brazil and the Politics of the Climate Change Negotiations." Journal of Environment and Development 10 (2): 178-206.

Kahan, Dan M., Ellen Peters, Maggie Wittlin, Paul Slovic, Lisa Larrimore Quellette, Donald Braman, and Gregory Mandel. 2012. "The Polarizing Impact of Science Literacy and Numeracy on Perceived Climate Change Risks." Nature Climate Change doi:10.1038/nclimate1547. 
Kemmelmeier, Markus, Grzegorz Król, and Young Hun Kim. 2002. "Values, Economics, and Proenvironmental Attitudes in 22 Societies." Cross-Cultural Research 36 (3): 256-285.

Knight, Kyle W., and Benjamin L. Messer. 2012. "Environmental Concern in Cross-National Perspective: The Effects of Affluence, Environmental Degradation, and World Society." Social Science Quarterly 93 (2): 521-537.

Lax, Jeffrey R., and Justin H. Phillips. 2009. "Gay Rights in the States: Public Opinion and Policy Responsiveness." American Political Science Review 103 (3): 367-386.

Liere, Kent D. Van, and Riley E. Dunlap. 1980. “The Social Bases of Environmental Concern: A Review of Hypotheses, Explanations and Empirical Evidence." Public Opinion Quarterly 44 (2): 181-197.

Liu, Jing, Zhiyun Ouyang, and Hong Miao. 2010. "Environmental attitudes of stakeholders and their perceptions regarding protected area-community conflicts: A case study in China." Journal of Environmental Management 91 (11): 2254 - 2262.

Martinelli, Luiz A., and Solange Filoso. 2008. "Expansion of Sugarcane Ethanol Production in Brazil: Environmental and Social Challenges." Ecological Applications 18 (4): 885-898.

Meadows, Donella H., Jorgen Randers, and Dennis L. Meadows. 2004. Limits to Growth: The 30-Year Update. White River Jct.: Chelsea Green.

Page, Benjamin I., and Robert Y. Shapiro. 1983. "Effects of Public Opinion on Policy." American Political Science Review 77 (1): 175-190.

Rabe, Barry, and Christopher Borick. 2009. "Public Opinion and Climate Change: Analysis of the Virginia Climate Survey." Virginia Environmental Law Journal 27 (3): 177-203.

Roberts, J. Timmons, and Bradley C. Parks. 2007. A Climate of Injustice: Global Inequality, NorthSouth Politics, and Climate Policy. Cambridge: MIT Press.

Rothman, Dale S. 1998. “Environmental Kuznets Curves-Real Progress or Passing the Buck? A Case for Consumption-Based Approaches." Ecological Economics 25 (2): 177-194.

Samuels, David. 2006. "Sources of Mass Partisanship in Brazil." Latin American Politics and Society 48 (2): 1-27.

Shukla, J., C. Nobre, and P. Sellers. 1990. "Amazon Deforestation and Climate Change." Science 247 (4948): 1322-1325.

Simon, Herbert A. 1997. Models of Bounded Rationality. Vol. 3 Cambridge, MA: MIT Press.

Stern, Paul C., Thomas Dietz, and Linda Kalof. 1993. "Value Orientations, Gender, and Environmental Concern." Environment and Behavior 25 (5): 322-348.

Tranter, Bruce. 1997. "Environmentalism and education in Australia." Environmental Politics 6 (2): 123-143.

Zelezny, Lynnette C., Poh-Pheng Chua, and Christina Aldrich. 2000. "New Ways of Thinking about Environmentalism: Elaborating on Gender Differences in Environmentalism." Journal of Social Issues 56 (3): 443-457. 
Table 1: Dependent Variables

\begin{tabular}{|c|c|c|}
\hline $\mathbf{Q}$ & Variable & Coding \\
\hline Q1 & Env in Candidate's Proposals & $\begin{array}{l}\text { When choosing whom to vote for, do you take into } \\
\text { account the candidate's proposals on the environ- } \\
\text { ment? } \\
\text { Never }=0 \\
\text { Rarely }=1 \\
\text { Sometimes }=2 \\
\text { Frequently }=3 \\
\text { Always }=4\end{array}$ \\
\hline Q2 & Sufficiency of Environmental Legislation & $\begin{array}{l}\text { In your opinion, environmental legislation in Brazil } \\
\text { is: } \\
\text { Too rigorous }=0 \\
\text { Adequate }=1 \\
\text { Too lenient }=2\end{array}$ \\
\hline Q3 & Allow Increase in Pollution Levels & $\begin{array}{l}\text { Do you agree or disagree with the following state- } \\
\text { ment? If it is important for the country's economic } \\
\text { development, the Brazilian government should allow } \\
\text { pollution to increase. } \\
\text { Agree }=0 \\
\text { Disagree }=1\end{array}$ \\
\hline Q4 & Env in Intl Negotiations & $\begin{array}{l}\text { When negotiating with other countries, how IMPOR- } \\
\text { TANT do you think Brazil should rate the environ- } \\
\text { ment? } \\
\text { Not important }=0 \\
\text { Not very important }=1 \\
\text { Very important }=2 \\
\text { DK/DA: missing }\end{array}$ \\
\hline
\end{tabular}


Table 2: Summary statistics

\begin{tabular}{|c|c|c|c|c|c|}
\hline & mean & sd & $\min$ & $\overline{\max }$ & count \\
\hline \multicolumn{6}{|c|}{ Dependent Variables } \\
\hline Env in Candidate's Proposals & 3.01 & 1.23 & 0 & 4 & 1170 \\
\hline Sufficiency of Environmental Legislation & 1.70 & 0.54 & 0 & 2 & 1188 \\
\hline Allow Increase in Pollution Levels & 0.93 & 0.25 & 0 & 1 & 1217 \\
\hline Env in Intl Negotiations & 1.91 & 0.34 & 0 & 2 & 1214 \\
\hline Factor Analysis Q1-Q4 & 0.00 & 0.53 & -3.34 & 0.42 & 1132 \\
\hline \multicolumn{6}{|c|}{ Independent Variables } \\
\hline Income & 2.42 & 0.98 & 1 & 5 & 1152 \\
\hline Education & 1.96 & 0.71 & 1 & 3 & 1219 \\
\hline Age & 3.62 & 1.56 & 1 & 6 & 1221 \\
\hline Female Respondent & 0.53 & 0.50 & 0 & 1 & 1226 \\
\hline Capital (Indicator) & 0.25 & 0.43 & 0 & 1 & 1226 \\
\hline Metro (Indicator) & 0.10 & 0.30 & 0 & 1 & 1226 \\
\hline
\end{tabular}


Table 3: Analysis of environmental preferences for a sample of Brazilian citizens.

\begin{tabular}{|c|c|c|c|c|c|c|c|c|c|c|}
\hline & \multicolumn{2}{|c|}{ Question 1} & \multicolumn{2}{|c|}{ Question 2} & \multicolumn{2}{|c|}{ Question 3} & \multicolumn{2}{|c|}{ Question 4} & \multicolumn{2}{|c|}{ Factor Analysis } \\
\hline & (1) & (2) & (3) & $(4)$ & $(5)$ & (6) & $(7)$ & (8) & (9) & (10) \\
\hline Income & $\begin{array}{c}0.009 \\
(0.042)\end{array}$ & $\begin{array}{c}0.007 \\
(0.046)\end{array}$ & $\begin{array}{l}-0.016 \\
(0.019)\end{array}$ & $\begin{array}{l}-0.008 \\
(0.021)\end{array}$ & $\begin{array}{c}0.022 \\
(0.142)\end{array}$ & $\begin{array}{c}0.097 \\
(0.171)\end{array}$ & $\begin{array}{l}-0.011 \\
(0.011)\end{array}$ & $\begin{array}{c}0.010 \\
(0.012)\end{array}$ & $\begin{array}{l}-0.019 \\
(0.019)\end{array}$ & $\begin{array}{c}0.003 \\
(0.020)\end{array}$ \\
\hline Education & $\begin{array}{c}0.204^{* * *} \\
(0.057)\end{array}$ & $\begin{array}{c}0.203^{* * *} \\
(0.059)\end{array}$ & $\begin{array}{l}0.051^{* *} \\
(0.024)\end{array}$ & $\begin{array}{l}0.050^{*} \\
(0.025)\end{array}$ & $\begin{array}{c}0.536^{* * *} \\
(0.200)\end{array}$ & $\begin{array}{l}0.485^{* *} \\
(0.213)\end{array}$ & $\begin{array}{c}0.045^{* * *} \\
(0.015)\end{array}$ & $\begin{array}{l}0.028^{*} \\
(0.015)\end{array}$ & $\begin{array}{c}0.123^{* * *} \\
(0.024)\end{array}$ & $\begin{array}{c}0.106^{* * *} \\
(0.025)\end{array}$ \\
\hline Age & & $\begin{array}{c}0.055^{* *} \\
(0.026)\end{array}$ & & $\begin{array}{c}0.009 \\
(0.012)\end{array}$ & & $\begin{array}{c}0.002 \\
(0.089)\end{array}$ & & $\begin{array}{c}-0.032^{* * *} \\
(0.008)\end{array}$ & & $\begin{array}{l}-0.012 \\
(0.012)\end{array}$ \\
\hline Female Respondent & & $\begin{array}{l}0.196^{* *} \\
(0.078)\end{array}$ & & $\begin{array}{c}0.088^{* *} \\
(0.034)\end{array}$ & & $\begin{array}{l}0.466^{*} \\
(0.276)\end{array}$ & & $\begin{array}{c}0.009 \\
(0.021)\end{array}$ & & $\begin{array}{c}0.104^{* * *} \\
(0.035)\end{array}$ \\
\hline Capital (Indicator) & & $\begin{array}{l}-0.103 \\
(0.096)\end{array}$ & & $\begin{array}{c}0.153^{* * *} \\
(0.035)\end{array}$ & & $\begin{array}{c}0.285 \\
(0.332)\end{array}$ & & $\begin{array}{l}-0.006 \\
(0.026)\end{array}$ & & $\begin{array}{c}0.043 \\
(0.037)\end{array}$ \\
\hline Metro (Indicator) & & $\begin{array}{l}-0.208 \\
(0.163)\end{array}$ & & $\begin{array}{c}0.048 \\
(0.062)\end{array}$ & & $\begin{array}{l}-0.876 \\
(0.547)\end{array}$ & & $\begin{array}{c}-0.042 \\
(0.051)\end{array}$ & & $\begin{array}{l}-0.081 \\
(0.072)\end{array}$ \\
\hline Constant & $\begin{array}{c}2.716^{* * *} \\
(0.353)\end{array}$ & $\begin{array}{c}2.462^{* * *} \\
(0.364)\end{array}$ & $\begin{array}{c}1.328^{* * *} \\
(0.157)\end{array}$ & $\begin{array}{c}1.215^{* * *} \\
(0.163)\end{array}$ & $\begin{array}{l}1.766^{*} \\
(1.035)\end{array}$ & $\begin{array}{c}1.366 \\
(1.066)\end{array}$ & $\begin{array}{c}1.874^{* * *} \\
(0.065)\end{array}$ & $\begin{array}{c}1.949^{* * *} \\
(0.069) \\
\end{array}$ & $\begin{array}{l}-0.248 \\
(0.179)\end{array}$ & $\begin{array}{c}-0.298 \\
(0.184)\end{array}$ \\
\hline State Fixed Effects & Yes & Yes & Yes & Yes & Yes & Yes & Yes & Yes & Yes & Yes \\
\hline$R^{2}$ & .04 & .05 & .05 & .07 & & & .03 & .05 & .04 & .05 \\
\hline$\sigma$ & 1.21 & 1.21 & .53 & .52 & & & .34 & .33 & .51 & .51 \\
\hline Observations & 1101 & 1099 & 1116 & 1114 & 1089 & 1087 & 1138 & 1136 & 1069 & 1067 \\
\hline
\end{tabular}

See text for the dependent variables. Columns 1-4 and 7-10: linear regressions. Columns 5-6: logistic regressions. Huber-White (robust) standard errors reported in parentheses.

${ }^{*} p<0.10,{ }^{* *} p<0.05,{ }^{* * *} p<0.01$ 
Table 4: Expanded analysis of environmental preferences for a sample of Brazilian citizens. Omitted baseline categories are the least educated and the poorest groups.

\begin{tabular}{|c|c|c|c|c|c|c|c|c|c|c|}
\hline & \multicolumn{2}{|c|}{ Question 1} & \multicolumn{2}{|c|}{ Question 2} & \multicolumn{2}{|c|}{ Question 3} & \multicolumn{2}{|c|}{ Question 4} & \multicolumn{2}{|c|}{ Factor Analysis } \\
\hline & $(1)$ & (2) & (3) & (4) & $(5)$ & (6) & $(7)$ & (8) & (9) & (10) \\
\hline \multirow[t]{2}{*}{ Up to 2 Minimum Wages } & 0.029 & 0.035 & 0.053 & 0.068 & -0.228 & -0.181 & $-0.048^{*}$ & -0.038 & -0.017 & 0.001 \\
\hline & $(0.114)$ & $(0.115)$ & $(0.048)$ & $(0.047)$ & $(0.363)$ & $(0.367)$ & $(0.029)$ & $(0.029)$ & $(0.041)$ & $(0.041)$ \\
\hline \multirow[t]{2}{*}{ 2-5 Minimum Wages } & $0.202^{*}$ & $0.218^{*}$ & 0.064 & $0.094^{*}$ & 0.210 & 0.403 & -0.017 & 0.020 & 0.044 & $0.097^{* *}$ \\
\hline & $(0.122)$ & $(0.127)$ & $(0.051)$ & $(0.055)$ & $(0.420)$ & $(0.454)$ & $(0.031)$ & $(0.032)$ & $(0.045)$ & $(0.046)$ \\
\hline \multirow[t]{2}{*}{ 5-10 Minimum Wages } & 0.016 & 0.011 & 0.048 & 0.066 & 0.173 & 0.368 & -0.030 & 0.028 & -0.003 & 0.053 \\
\hline & $(0.160)$ & $(0.164)$ & $(0.070)$ & $(0.073)$ & $(0.569)$ & $(0.629)$ & $(0.038)$ & $(0.040)$ & $(0.059)$ & $(0.061)$ \\
\hline \multirow[t]{2}{*}{ >10 Minimum Wages } & -0.125 & -0.113 & $-0.207^{*}$ & -0.183 & -0.482 & -0.214 & -0.090 & -0.016 & $-0.238^{*}$ & -0.152 \\
\hline & $(0.241)$ & $(0.251)$ & $(0.115)$ & $(0.117)$ & $(0.691)$ & $(0.777)$ & $(0.064)$ & $(0.068)$ & $(0.143)$ & $(0.147)$ \\
\hline \multirow[t]{2}{*}{ Secondary Education } & $0.302^{* * *}$ & $0.338^{* * *}$ & $0.106^{* * *}$ & $0.113^{* * *}$ & $0.717^{* *}$ & $0.685^{* *}$ & $0.059^{* *}$ & 0.030 & $0.175^{* * *}$ & $0.160^{* * *}$ \\
\hline & $(0.098)$ & $(0.101)$ & $(0.040)$ & $(0.042)$ & $(0.288)$ & $(0.304)$ & $(0.028)$ & $(0.029)$ & $(0.042)$ & $(0.043)$ \\
\hline \multirow[t]{2}{*}{ Tertiary Education } & $0.383^{* * *}$ & $0.377^{* * *}$ & $0.096^{*}$ & $0.097^{*}$ & $0.850^{* *}$ & $0.738^{*}$ & $0.078^{* * *}$ & 0.042 & $0.226^{* * *}$ & $0.191^{* * *}$ \\
\hline & $(0.114)$ & $(0.117)$ & $(0.049)$ & $(0.052)$ & $(0.392)$ & $(0.413)$ & $(0.029)$ & $(0.029)$ & $(0.048)$ & $(0.051)$ \\
\hline \multirow[t]{2}{*}{ Age } & & $0.059^{* *}$ & & 0.012 & & 0.008 & & $-0.033^{* * *}$ & & -0.011 \\
\hline & & $(0.026)$ & & $(0.012)$ & & $(0.090)$ & & $(0.008)$ & & $(0.012)$ \\
\hline \multirow[t]{2}{*}{ Female Respondent } & & $0.220^{* * *}$ & & $0.094^{* * *}$ & & $0.512^{*}$ & & 0.012 & & $0.113^{* * *}$ \\
\hline & & (0.077) & & $(0.035)$ & & $(0.275)$ & & $(0.021)$ & & $(0.035)$ \\
\hline \multirow[t]{2}{*}{ Capital (Indicator) } & & -0.101 & & $0.157^{* * *}$ & & 0.300 & & -0.007 & & 0.044 \\
\hline & & $(0.096)$ & & $(0.036)$ & & $(0.330)$ & & $(0.026)$ & & $(0.037)$ \\
\hline \multirow[t]{2}{*}{ Metro (Indicator) } & & -0.206 & & 0.053 & & -0.900 & & -0.044 & & -0.081 \\
\hline & & $(0.164)$ & & $(0.062)$ & & $(0.552)$ & & $(0.051)$ & & $(0.073)$ \\
\hline \multirow[t]{2}{*}{ Constant } & $2.823^{* * *}$ & $2.514^{* * *}$ & $1.281^{* * *}$ & $1.149^{* * *}$ & $2.404^{* *}$ & $1.933^{*}$ & $1.922^{* * *}$ & $2.011^{* * *}$ & -0.187 & -0.246 \\
\hline & $(0.347)$ & $(0.363)$ & $(0.150)$ & $(0.157)$ & $(1.095)$ & $(1.140)$ & $(0.063)$ & $(0.070)$ & $(0.173)$ & $(0.181)$ \\
\hline State Fixed Effects & Yes & Yes & Yes & Yes & Yes & Yes & Yes & Yes & Yes & Yes \\
\hline $\mathrm{R}^{2}$ & .05 & .06 & .06 & .08 & & & .03 & .05 & .05 & .07 \\
\hline$\sigma$ & 1.21 & 1.21 & .53 & .52 & & & .34 & .33 & .51 & .51 \\
\hline Observations & 1101 & 1099 & 1116 & 1114 & 1089 & 1087 & 1138 & 1136 & 1069 & 1067 \\
\hline
\end{tabular}

See text for the dependent variables. Columns 1-4 and 7-10: linear regressions. Columns 5-6: logistic regressions.

Huber-White (robust) standard errors reported in parentheses.

${ }^{*} p<0.10,{ }^{* *} p<0.05,{ }^{* * *} p<0.01$ 